profession." The report recommends that the autonomous bodies should in fact remain so, and they would submit reports to the Representative Body "for information and not normally for detailed discussion." Any member of the B.M.A. would retain the right to challenge, through his Division, the actions of an autonomous body-as of the Representative Body itself. But when the Representative Body wishes to exercise its right to disagree with an autonomous body "it would normally refer the matter back to the autonomous body before reaching a final decision." These arrangements, backed by a reconstituted Representative Body, should go far to allow consent to prevall over conflict within the profession.

\section{Epidemic Hysteria}

Mass outbreaks of alterations of consciousness, seizures, hyperventilation, and severe emotional upsets were much commoner in the Middle Ages than they are today, at least in Europe. Their frequency declined as it became generally recognized that the symptoms were due to mental disturbance and not to the work of the Devil or other supernatural influences. $^{1}$ But epidemics do recur from time to time when conditions are propitious.

At page 1295 of the B.M.F. Drs. P. D. Moss and C. P. McEvedy describe an outbreak of hysteria which occurred among the girls of a school at Blackburn last year, and in a paper at page 1300 Drs. C. P. McEvedy, A. Griffith, and T. Hall discuss outbreaks at two other schools. The Blackburn outbreak lasted on and off for twelve days and was remarkable for the number of girls affected. It afforded a unique opportunity for studying at first hand some of the factors responsible for such an outbreak.

All accounts of epidemic hysteria show that symptoms occur within a unified group against a background of fear and ignorance, and are triggered off by some particular event. The Blackburn outbreak was no exception. In the early part of last year there had been an epidemic of poliomyelitis in the town, widely publicized by the press. To the disquiet of the townsfolk caused by reports of the epidemic and its dangers was added a sense of isolation because some seaside hoteliers were said to be refusing to take holidaymakers from Blackburn and lorry drivers to deliver supplies to the town. All this prepared the ground, so that when, at a three-hour ceremony attended by the whole school, a number of girls fainted, the scene was set for the outbreak of mass hysteria which began next day at school. Doubtless the publicity immediately given to the " mysterious illness" helped to increase the anxiety of the schoolgirls and their families and probably contributed to the recrudescence of symptoms when the school reassembled.

Epidemic hysteria has always tended to involve women more than men, particularly those in the younger age groups. Few men, for instance, were affected in the dancing manias which recurred from time to time throughout Europe in the Middle Ages. In the Blackburn epidemic symptoms first began among 14-year-old girls and rapidly spread to affect most heavily the youngest, and therefore more susceptible,

\footnotetext{
1 Veith, I., Hysteria: The History of a Disease, 1965. University of Chicago Press.

Jaspers, K., General Psychopathology, trans. J. Hoenig and M. W. Hamilton, 1962, p. 735. Manchester University Press.

- Slater, E., Brit. med. F., 1965, 1, 1395.

- Walshe, Sir F., ibid., 1965, 2, 1451.
}

girls. Some clearly showed themselves to be more susceptible than others irrespective of age.

The best way to bring an epidemic of hysteria to an end is to let it be known as quickly, widely, and emphatically as possible that all symptoms have no physical cause but are emotional in origin. It is also wise to give those affected as little publicity as possible. These were the actions commonly adopted in dealing with the outbreaks of hysteria which so frequently attacked convents in the sixteenth and seventeenth centuries. When the bishop ordered the affected nuns to be put under house arrest and isolated, the epidemic quickly died out, whereas if public exorcism of the Devil was carried out by priests the epidemic grew rapidly. ${ }^{2}$ Understandably at Blackburn, where the diagnosis could be reached only after thorough studies unknown to earlier centuries, it must have been difficult to act on these principles, particularly when some parents are apt to seek litigation and the general public to be indignant at a diagnosis of hysteria. It is never easy to diagnose hysteria, for the diagnosis usually has to be made by exclusion, without positive evidence. Indeed the existence of a disorder with that title has recently been denied, ${ }^{3}$ and affirmed. ${ }^{4}$ In the Blackburn epidemic the typical pattern of events preceding the outbreak, the way symptoms developed only at school in a manner difficult if not impossible to explain by any physical cause, and the fact that the girls' symptoms were entirely explicable in terms of overbreathing due to emotional tension made hysteria the most likely diagnosis after the first day or so. But clearly at the start of any epidemic it is essential to exclude causes such as food-poisoning or viral infections. Having done so, the medical attendants can then reassure all and sundry, loudly and firmly.

The Blackburn epidemic was large, and because of this achieved much publicity. It is perhaps pertinent to wonder how frequently small and short-lived epidemics of hysteria occur. Were there no manifestations of hysteria in Aberdeen after the much publicized typhoid epidemic in 1964? How often are the outbreaks of usually undiagnosed illnesses which occur from time to time among nurses in training, affecting no one else, really hysterical ? Clearly further research into these problems along the lines indicated by Drs. Moss and McEvedy is desirable.

\section{Gout and Diabetes Mellitus}

In some way gout and diabetes mellitus seem to be associated. In $1768 \mathrm{R}$. Whytt ${ }^{1}$ hinted at a relationship when he described a patient with "gouty arthritis" who developed polyuria. Some of the great physicians of the nineteenth century such as Trousseau, $^{2}$ A. E. Garrod, ${ }^{3}$ Claude Bernard, ${ }^{2}$ and Charcot ${ }^{4}$ also noted an apparent association.

Recently F. W. Whitehouse and W. J. Cleary ${ }^{5}$ reported that $10 \%$ of their patients with gout also had diabetes mellitus. They found, however, that of 89 patients with both conditions no fewer than $83 \%$ did not require insulin therapy. Incidentally most of these patients were obese. It is important to recognize that the diagnosis of diabetes mellitus was made as a result of routine screening by estimations of blood glucose two hours after the ingestion of $100 \mathrm{~g}$. of carbohydrate, and that one-third of patients so diagnosed had asymptomatic, "chemical" diabetes only.

A $10 \%$ incidence of diabetes mellitus in gouty patients is in agreement with previous reports. ${ }^{67} \mathrm{~W} . \mathrm{K}$. Ishmael and 
colleagues $^{8}$ found a similar incidence, though all their patients suffered from clinical diabetes. Assessing the incidence of diabetes in patients with gout on the basis of raised bloodsugar levels (either fasting or during glucose-tolerance tests), T. E. Weiss and colleagues ${ }^{9}$ found an incidence of $28 \%$ (compared with $19 \%$ in controls).

These figures must be viewed in the light of the incidence of diabetes in the general population. In 1963, for example, a working party appointed by the College of General Practitioners reported in this journal that $6.2 \%$ of the population, and no fewer than $14.5 \%$ of those over 50, were found to have a diabetic abnormality of the glucose-tolerance test. ${ }^{10}$ From the results of the Diabetes Survey in Bedford, C. L. Sharp and colleagues ${ }^{11}$ estimate the overall national incidence of diabetes mellitus to be $12-14 \%$.

The incidence of gout in diabetic patients is also of interest. Both Whitehouse and Cleary and A. G. Beckett and J. G. Lewis ${ }^{7}$ found that $1 \%$ of their patients with diabetes mellitus had gout. In general populations of European stock about $0.5 \%$ are found to develop clinical gout, ${ }^{12}{ }^{13}$ and indeed the incidence of hyperuricaemia (above $6 \mathrm{mg}$. per $100 \mathrm{ml}$.) is as high as $13 \%$ in females and $4.6 \%$ in males. ${ }^{12}$

Even if the association between diabetes and gout is not fortuitous the mechanism by which they are related is unknown. Most of the cases of diabetes mellitus have been of the obese "maturity-onset" type, and few have required insulin. Obesity as a causative factor in gout has been noted for many years. I. A. M. Prior and his colleagues, ${ }^{14}$ in a survey of New Zealand Maoris, found a high incidence of hyperuricaemia and clinical gout, diabetic abnormality, and excess weight in both sexes. Diet may raise the serum uric acid by up to $2 \mathrm{mg}$. per $100 \mathrm{ml}$.- -an amount sufficient to produce clinical gout in a previously mildly hyperuricaemic person. ${ }^{15}$ Moreover, the incidence of both the "maturityonset" form of diabetes mellitus and gout rises sharply in late middle age.

What chemical mechanisms could relate gout and diabetes mellitus? Firstly, uric acid has a chemical similarity to

\footnotetext{
Whytt, R., The Works of Robert Whytt, 1768, pp. 557, 708. Edin-

- Trousseau, A., Lectures on Clinical Medicine, 1870, Vol. 3, p. 497. New Sydenham Society, London.

- Garrod, A. B., A Treatise on Gout and Rheumatic Gout, 1876, 3rd ed., p. 472. London.

Charcot, J. M., Clinical Lectures on Senile and Chronic Diseases, 1881, p. 99. New Sydenham Society, London.

-Whitehouse, F. W., and Cleary, W. J., jun., f. Amer. med. Ass., 1966, $197,73$.

- Herman, J. B., Metabolism, 1958, 7, 703.

- Beckett, A. G., and Lewis, J. G., Quart. F. Med., 1960, 29, 443

- Ishmael, W. K., Owens, J. N., jun., Payne, R. W., and Honick, M. D. F. Amer. med. Ass., 1964, 190, 396.

- Weiss, T. E., Segaloff, A., and Moore, C., Metabolism, 1957, 6, 103

10 Report of a Working Party appointed by the College of General PractiReport of a Working Party appointed by
tioners, Brit. med. 7 ., 1963, 2, 655.

" sharp, C. L., Butterfield, W. J. H., and Keen, H., Proc. roy. Soc. Med., 1964, 57, 193.

12 Popert, A. J., and Hewitt, J. V., Ann. rheum. Dis., 1962, 21, 154.

Lennane, G. A. Q., Rose, B. S., and Isdale, I. C., ibid., 1960, 19 120.

Prior, I. A.

1065. Dixon, A. St. J., in Progres

10 Griffiths. M., $\dot{f}$. biol. Chem., 1950, 184, 289.

: Dunn, J. S., Sheehan, H. L., and McLetchie, N. G. B., Lancet, 1943, $1,484$.

1" Collins-Williams, J., and Bailey, C. C., Proc. Soc. exp. Biol. (N.Y.) 1949, 71, 583.

1 Padova, J., and Bendersky, G., New Engl. f. Med., 1962, 267, 530.

Goldfinger, S., Klinenberger, J. R., and Seegmiller, J. E., ibid.. 1965 272, 351 .

¿ Scott, J. T., McCallum, F. M., and Holloway, V. P., Clin. Sci., 1964, 27, 209.

2 Berkowitz, D., f. Amer. med. Ass., 1966, 197, 77.

ss - ibid., 1964, 190, 856.

* Bartels, E. C., Balodimos, M. C., and Corn, L. R., Med. clin. N. Amer., 1960, 44, 433.
}

alloxan, ${ }^{16}$ which can induce diabetes by necrosis of the $\beta$-cells of the islets of Langerhans. ${ }^{17}$ And, though large injections of uric acid have been reported to induce diabetes in rabbits in certain circumstances, ${ }^{16}$ similar experiments ${ }^{18}$ failed to confirm this result. Thus a diabetogenic effect of uric acid remains unproved. Secondly, it is known that ketoacidosis will produce hyperuricaemia by reducing the renal clearance of urate. This can be seen in cases of diabetic ketoacidosis ${ }^{19}$ by giving infusions of ketones into normal persons ${ }^{20} 21$ and by starvation of normal persons. ${ }^{21}$ But since gout frequently develops before the diabetes, and since the diabetes, when it occurs, is usually mild, this explanation seems unconvincing.

A third possible chemical mechanism has been described by $\mathrm{D}$. Berkowitz. ${ }^{22}$ In 1964 he reported ${ }^{23}$ a correlation between hyperuricaemia and hypertriglyceridaemia, and he now proposes that there is a primary association between hypertriglyceridaemia and reduced glucose tolerance. ${ }^{22}$ This suggests a possible link between hyperuricaemia and diabetes through an abnormality of triglyceride metabolism. He may be right, though perhaps changes common to both diabetes mellitus and gout-for example, obesity and increasing age -could themselves produce abnormalities of triglyceride metabolism.

The development of diabetes has been said to improve clinical gout, ${ }^{24}$ and it is interesting that Garrod noted this in $1876 .^{3}$ Conversely hyperuricaemia may diminish the clinical expression of diabetes. ${ }^{5}$ Ishmael and his colleagues ${ }^{8}$ claim that before 1944 diabetes was rarely seen in association with gout, and some of the recent reports have suggested that the lowering of the serum uric acid level by modern uricosuric drugs could be revealing the diabetic state. There is certainly no evidence that uricosuric drugs are themselves diabetogenic.

It would seem clear that the association of gout and diabetes mellitus is not uncommon. Whether it is fortuitous or not, it might be advisable to add blood-sugar estimations to the routine investigations of a patient with gout.

\section{Diffuse Interstitial Pulmonary Fibrosis}

Two decades have passed since the last of three papers by L. Hamman and A. R. Rich ${ }^{1}$ brought to light a previously unrecognized disorder-namely, diffuse interstitial pulmonary fibrosis. In that time it has become apparent, from many published reports, that the acute form which they described is less common than the chronic form. The disease is now known to occur at all ages and even in infancy. Only very occasionally does the patient recover. The diagnosis need not now await necropsy; it can be made with some confidence in life on clinical and radiological findings, and in typical cases even lung biopsy has become unnecessary.

An excellent review by J. L. Livingstone and colleagues ${ }^{2}$ outlined the development of our knowledge of the subject and described 45 cases in adults. The story is nearly always of progressive dyspnoea with an irritable dry cough but no fever. In the lungs post-tussive rales are heard without expiratory wheezing. Clubbing of the fingers (in two-thirds of the

\footnotetext{
1 Hamman, L., and Rich, A. R., Bull. Fohns Hopk. Hosp., 1944, 74, 177.

Livingstone, J. L., Lewis, J. G., Reid, L., and Jefferson, K. E., Quart. F. Med., 1964, 33, 71

Midwinter, R E., Apley, J., and Burman, D., Arch. Dis. Childh., 1966, 41, 295.
} 